\title{
BEHAVIOUR OF POLYMER MATRIX COMPOSITE UNDER DIFFERENT ENVIRONMENTAL CONDITIONS
}

\author{
Saurabh Pathak; Shubendra Nath Shukla;Vikas Chaudhary; Kaushalendra Kr Dubey \\ Department of Mechanical \& Automobile Engineering, \\ Sharda University, Greater Noida, U.P. I \\ Email: vikas24693@gmail.com
}

\begin{abstract}
Polymer-matrix composites (PMC) have been used for a variety of structural memberships for chemical plants and airplanes, since they have outstanding performances, such as lightweight and good fatigue properties. To hold the long-term durability and to estimate the residual life of the composites under some hostile environments, it is an important issue to clarify the facture and/or the failure mechanism in each service conditions. The main concern of this paper will be to examine the causes of degradation of polymeric components under different environment.
\end{abstract}

Keywords-PMC, Tensile Loading Freezing Point.,

\section{Introduction}

Composite material, as the name suggest, is a combination of two or more materials which are combined on a macroscopic scale to form a useful material. The constituent materials have significantly different physical and chemical properties and remain separate in the final structure. These materials are ideal for structural applications where high strength-to-weight and stiffness-to-weight ratio are required. Composites are hybrid materials made of a polymer resin reinforced by fibres, combining the high mechanical and physical performance of the fibres and the appearance, bonding and physical properties of polymers [1].

1.1 Polymer Matrix Composites (PMC's) - These are the most common and will the main area of discussion in this guide. Also known as FRP- Fibre Reinforced Polymers- these materials use a polymer-based resin as the matrix, and a variety of fibres such as glass, carbon and aramid as the reinforcement.

1.2 FRP Composites - A generic FRP system will constitute a matrix and reinforcement in a fibrous form. The use of fibre as high performance engineering materials is based on three important characteristics;

(i) A small diameter with respect to its grain size or other micro structural unit. This allows a higher fraction of the theoretical strength to be attained than is possible in a bulk form. This is a direct result of the so-called "size-effect", which is , the smaller the grain size, the lower the probability of having the impurities in the material. It has been shown, that the strength of the carbon fibre decreases as its diameter increases. The general trend may be linear or non-linear.

(ii) A high aspect ratio (length/diameter), which allow a very large fraction of the applied load to be transferred via the matrix to the strong and stiff fibres.

(iii) A very high degree of flexibility, which is really a characteristic of a material that has a high modulus and a small diameter. This flexibility permits use of variety of techniques for making composites with these fibers [2].

\subsection{Reinforcement material}

The primary function of fibres or reinforcements is to carry load along the length of the fibre to provide strength and stiffness in one direction. Reinforcements can be oriented to provide tailored properties in the direction of the loads imparted on the end product. Reinforcements can be both natural and man-made[3]. Many materials are capable of reinforcing polymers. Some materials, such as the cellulose in wood, are naturally occurring products. Most commercial reinforcements, however, are man-made. Of these, by far the largest volume reinforcement measured either in quantity consumed or in product sales, is glass fibre. Other composite reinforcing materials include carbon, aramid, UHMW (ultra high molecular weight) polyethylene, polypropylene, polyester and nylon. Carbon fibre is sometimes referred to as graphite fibre. More specialized reinforcements for high strength and high temperature use include metals and metal oxides such as those used in aircraft or aerospace applications. 


\section{Methodology}

There are a wide variety of processes available to the composites manufacturer to produce FRP products. Each of the fabrication processes has characteristics that define the type of products to be produced FRP laminates can be made by a number of primary manufacturing processes for composite materials.[4] Hand lay-up, compression molding, pultrusion, Resin Transfer Molding (RTM), Vacuum Assisted Resin Transfer Molding (VARTM) etc. can be used to make laminates. A survey of the facilities available was carried out and it was decided to make the laminate using the hand lay-up technique. [5]

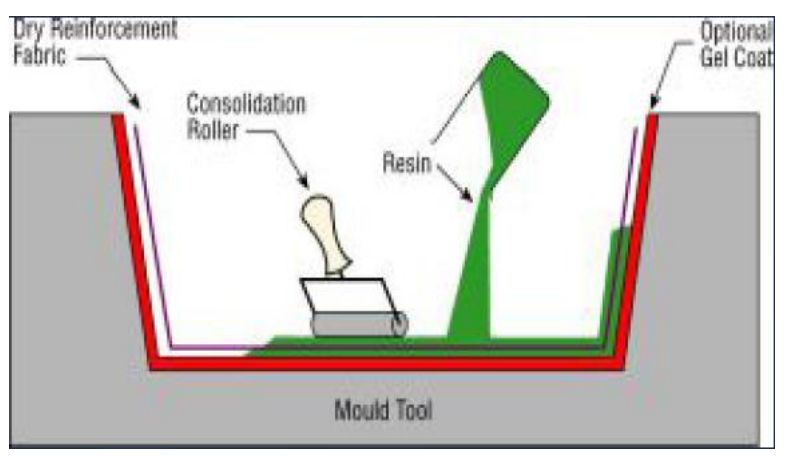

Fig. 1 Hand Lay Up Process

The material selected for the fabrication of flat plate mold was mild steel. The flat plate mold was fabricated using the standard processes of shaping, drilling and welding. Grinding of the faces of both the plates was done in order to attain high degree of surface finish. Surface finish of the faces becomes important to impart a smooth surface on the laminates. The matching of the two flat plates of the mold was done using the dowels and nut-bolt arrangement was used to apply. [6]

\section{Testing and Result}

Volume fraction is an important parameter that gives a fair amount of idea about the degree of reinforcement that has been done by the addition of fibres. The mechanical properties of the FRP composites strongly depend on the fibre-volume fraction. Burnout test was performed to find out the value of fibre-volume fraction. The burning process was accomplished in the Muffle furnace. The weighing of the specimen was carried out on digital weighing machine having an accuracy of 0.001gm. [7]
The samples to test by burnout were taken from different section of the GFRP composite laminate to randomize any sort of error. Volume fraction of GFRP is carried on muffle furnace. This procedure is known as burn out operation or ignition loss method. According to (American society of testing material) ASTM D2584 standard test method for ignition loss method cured reinforced resin. Three samples GFRP are taken according to standard and then heated at a temperature of $650 \mathrm{C}$ for ten minutes and it was then cooled to room temperature and its mass was determined. [8]

After burn out operation volume fraction of the ranged from 34.75 to 36.12 so the average glass fibre volume fraction comes $35.71 \%$.[9]

\section{ENVIRONMENTAL CONDITIONS AND IMPACT}

\section{a). Effect of $\mathrm{NaOH}$}

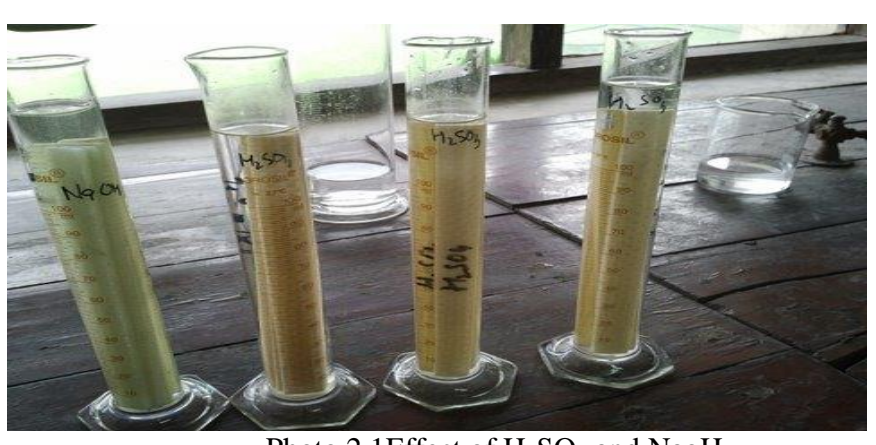

Photo 2.1Effect of $\mathrm{H}_{2} \mathrm{SO}_{4}$ and $\mathrm{NaoH}$

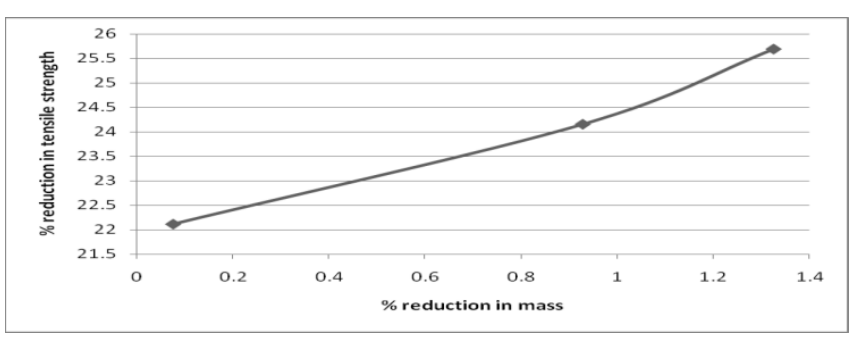

Fig 2.2 Percentage variation of tensile strength with decrease in weight while dipping in $\mathrm{NaOH}$ 


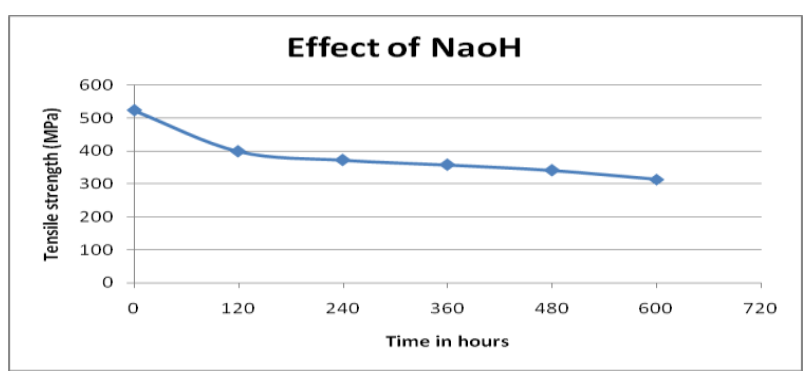

Fig2.3Effect of $\mathrm{NaoH}$ on tensile strength with respect to time

\section{b).Effect of $\mathrm{H}_{2} \mathrm{SO}_{4}$}

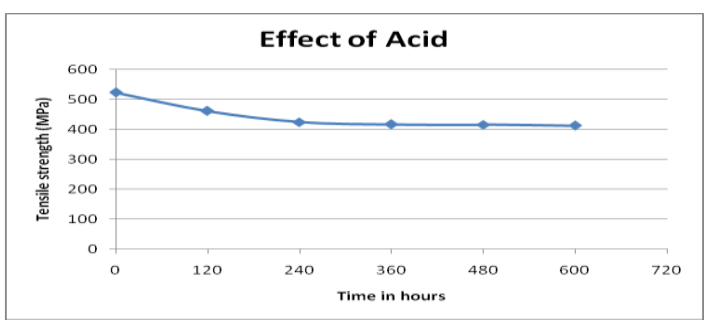

Fig 2.4Effect of $\mathrm{H}_{2} \mathrm{SO}_{4}$ on tensile strength with respect to time

\section{c). Effect of freezer conditions}

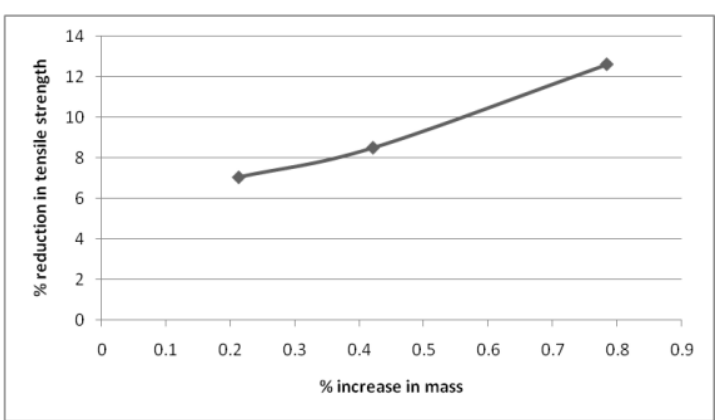

Fig.2.5 Variation of tensile strength with increase in weight in freezing condition

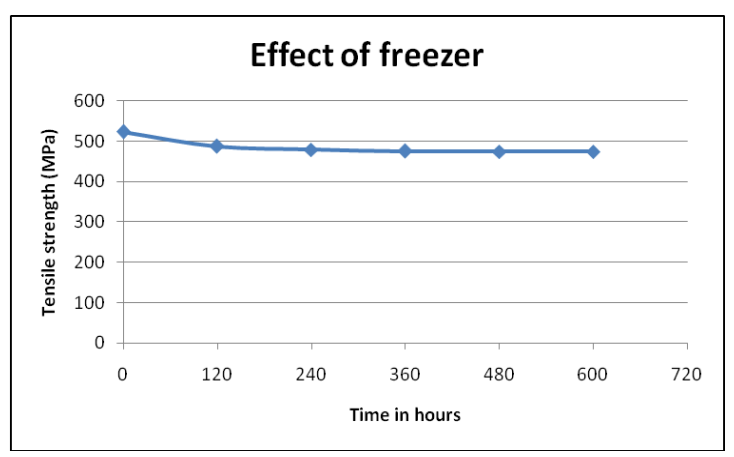

Fig.2 6. Effect of freezer environment on tensile strength d).Effect of brine solution

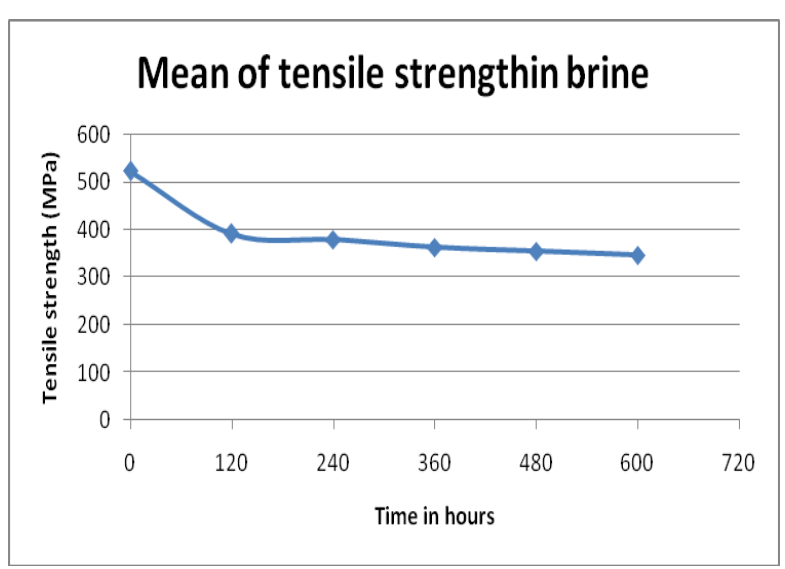

Fig2.7 Effect of brine solution on tensile strength

\section{CONCLUSIONS}

The effect of various environmental conditions on tensile strength of glass fibre reinforced composite were investigated.

(i) The tensile strength decreases and percentage reduction increases after every time interval because of attack of $\mathrm{NaOH}$ on epoxy resin.

(ii) The effect of acid will increase the percentage reduction because inter phase deboning, and matrix swelling of PCM material cause reduction in tensile strength.

(iii) It is observed that the tensile strength in freezing conditions is almost the same as in sukhna lake water. Degradation in tensile strength is low in freezing condition because of low moisture uptake so Polymer matrix can be used in low temperature applications.

(v)The PMC's material when subjected to $\mathrm{NaOH}$ solution showed the maximum percentage Reduction in tensile strength whereas minimum percentage reduction was found for exposure to freezing environmental condition.

\section{REFERENCES}

1. Gu Huang and Hongxia Sun, "Effect of water absorption on the mechanical properties of glass/polyester composites" Materials and Design 28 (2007) 1647-1650

2. M. Raghavendra1, C.M. Manjunatha, "effect of moisture on the mechanical properties of GFRP composite fabric material" International Symposium of Research Students on Material Science and Engineering (2004) 
3. Rui Miranda Guede, "Prediction of long-term behaviour of composite materials" Computers and Structures 76 (2000) 183-194

4. Alaattin Aktas, "Sea water effect on pinnedjoint glass fibre composite materials" Composite Structures 85 (2008) 59-63

5. T.J. Myers, "Environmental stress-corrosion cracking of fibreglass:

Lessons learned from failures in the chemical industry" 142 (2007) 695-704 Journal of Hazardous Materials

6. D. Olmos, "The nature of the glass fibre surface and its effect in the water absorption of glass fibre/epoxy composites. The use of fluorescence to obtain information at the interface", Composites Science and Technology 66 (2006) 2758-2768

7. Yunn-Tzu Yu, "Modeling long-term degradation due to moisture and oxygen in Polymeric matrix composites" Materials Science and Engineering (2008)

8. A. PAILLOUS and C. PAILLER, "Degradation of multiply polymer-matrix composites induced by space environment"( 1993)

9. Abdalla F. H., "Determination of volume fraction values of filament wound glass and carbon fibre reinforced composites" VOL. 3, NO. 4, AUGUST 2008

10. Salar Bagherpour, "Effects of concentrated $\mathrm{HCl}$ on the mechanical properties of storage aged fibre glass polyester composite" Materials and Design 30 (2009) 271-274 